\title{
INFÂNCIA E MORTE NA REGIÃO CARBONÍFERA: OS DISCURSOS MÉDICOS SANITÁRIOS SOBRE A MORTALIDADE INFANTIL NO SUL DE SANTA CATARINA
}

\author{
Infancy and death in the coal-mining region: \\ medical-sanitary discourses about infant mortality \\ rate in southern Santa Catarina
}

\author{
Ismael Gonçalves Alves*
}

\begin{abstract}
RESUMO
O artigo proposto tem por objetivo analisar os discursos médicosanitários sobre a mortalidade infantil na Região Carbonífera Catarinense. Desde o início do período republicano a infância e a maternidade paulatinamente vinham ocupando destacado espaço entre os discursos de burocratas, médicos, filantropos e empresários, que viam na infância saudável a possibilidade de transformar a nação em uma potência industrial e militar. Não diferente do restante do país, na Região Carbonífera Catarinense em pleno processo de modernização econômica, entre as décadas de 1940 e 1960, a saúde das crianças foi alvo de um importante processo de intervenção que visava inventariar a causa dos elevados números da mortalidade infantil na região, transformando a família trabalhadora e pobre no alvo de inúmeros discursos normativos que os responsabilizava por tal situação médico-sanitária, transformando as mães em principais culpadas pelas mortes que assolavam a população pueril.
\end{abstract}

Palavras-chave: Infância; Mortalidade; Medicina

* Professor do Curso de História e do Programa de Pós-Graduação em Desenvolvimento Socioeconômico da Universidade do Extremo Sul Catarinense - UNESC. e-mail de contato: iga@unesc.net. 


\begin{abstract}
The purpose of this article is to analyze medical-sanitary discourses about infant mortality in the coal-mining region of Santa Catarina. Since the beginning of the republican period infancy and motherhood gradually occupied a highlighted space among the discourses of bureaucrats, physicians, philanthropists and businessmen, who saw in a healthy childhood the possibility to transform the nation into an industrial and military potency. Similar to the rest of the country, in the coal-mining region of Santa Catarina, in its full process of economic modernization between the decades of 1940 and 1960, children's health was the target to an important intervention process which aimed at cataloging the causes of the high rates of infant mortality in the region, thus making the working and poor families subjects to countless normative discourses that held them accountable for the medical-sanitary situation, turning the mothers in to the main culprits for the deaths that ravaged the puerile population.
\end{abstract}

Key-words: Infancy; Childhood; Mortality; Medicine

\title{
O problema da infância no Brasil: notas introdutórias
}

A criança como problema de Estado emerge no Brasil com maior envergadura entre os anos de 1930 e 1960, quando alinhado ao contexto internacional o país paulatinamente propôs uma agenda positiva em favor da infância. Alvo do discurso médico, pedagógico, assistencial e jurídico, a criança e suas inúmeras representações sociais, como a delinquente, a abandonada, a ociosa e a desvalida, foi pouco a pouco se transformando em alvo preferencial de sistemas de proteção social, públicos e privados, que buscavam a todo custo salvaguardar este grupo etário.

Pressionado por homens e mulheres engajados, o poder público em seus diversos níveis administrativos foi obrigado a se posicionar de maneira clara sobre quais seriam as políticas sociais destinadas à proteção à infância e à maternidade em todo país, em uma tentativa de equiparar o Brasil às grandes nações desenvolvidas do Ocidente. 
Se num primeiro momento os cuidados com a infância e com a maternidade eram entendidos como problemas individuais a serem sanados no âmbito familiar, a partir dos anos de 1930 eles passam a ser indiscutivelmente uma atribuição do Estado. Solapada pelos efeitos da Crise de 1929 e pelo clima bélico do período entre guerra, as décadas seguintes obrigaram diversos países a assegurarem ou reelaborarem suas legislações de proteção às mães e às crianças, implantando mecanismos institucionais que regulassem o trabalho infantil, que garantissem o repouso à operária gestante e que instaurassem sistemas sanitário-assistenciais que atendessem, principalmente, as camadas mais pobres da população. Este modelo assistencial estava ancorado na ideia de nacionalidade e de criação do novo homem brasileiro, ou seja, proteger as mães e as crianças significava resguardar a própria nação, modelando o futuro cidadão para mudar os rumos do país.

Se no Brasil, durante os anos que antecederam a década de 1930, os serviços voltados à maternidade e infância eram quase todos administrados e financiados por instituições filantrópicas surgidas pela iniciativa de médicos como Moncorvo Filho, Fernandes Figueira, Olinto de Oliveira e Martagão Gesteira, nas décadas posteriores tais serviços passam a ser institucionalizados por órgãos públicos. Críticos do Estado negligente e desinteressado, responsável pela situação de abandono material e moral das crianças e suas mães pobres, médicos, filantropos e o movimento de mulheres exigiam que o governo garantisse o mínimo de assistência necessária para salvaguardar esta parcela da população. Conforme advertia Olinto de Oliveira sobre as responsabilidades do ente público:

Compete ao Estado [...] fazer a política da criança atenuando ou eliminando a desigualdade das suas condições sociais protegendo-as diretamente por medidas 
adequadas e indiretamente amparando a família e a maternidade, e promovendo a assistência social. ${ }^{1}$

O reposicionamento do governo brasileiro em defesa da maternidade e da infância foi impulsionado principalmente pela abertura da burocracia estatal a um corpo especializado de médicos e puericultores que assumiram o comando dos serviços assistenciais, bem como pelo movimento de mulheres, que organizado estimulou e racionalizou o atendimento aos necessitados. No entanto, tal burocracia, extremamente masculinizada, possuía pouca simpatia pelas reivindicações feministas de emancipação e reconhecimento social que pudessem ser pleiteados por meio da valorização da maternidade.

Este discurso em defesa da criança e da mãe, próprio do maternalismo, foi ressignificado pela burocracia estatal encarregada de formular as políticas públicas assistenciais e por meio de um discurso de gênero pouco equitativo que naturalizou a maternidade, transformando-a em uma obrigação biológica e moral da mulher com a Pátria e o Estado nacional.

Ao naturalizar a maternidade e torná-la uma das funções exclusivas das mulheres para com o país, a legislação específica não reconhecia a cidadania per se, que só era reconhecida em sua plenitude quando as mães estavam inseridas no mercado de trabalho ou estivessem vinculadas a um homem trabalhador pelo casamento, excluindo dos sistemas de ajuda estatal mães solteiras, separadas, pobres e desempregadas, que por sua vez estavam a cargo da filantropia.

Parte da ideia de ampliar o amparo à maternidade e à infância, além de seu inegável cunho humanitário, estava associada a uma tentativa de regulação dos grupos familiares, definindo a partir das políticas assistenciais as identidades de gênero de seus membros: o homem provedor, o maior beneficiário da assistência; a mulher 
esposa e mãe que recebia assistência indireta e as crianças, indiscutivelmente assistidas por seu vir a ser.

Esta regulação, principalmente para as mães e as crianças, estendia-se por uma ampla rede de benefícios, que além de fornecer o amparo social contribuía para a manutenção dos papéis de gênero. Por meio da assistência especializada de médicos, de visitadoras sanitárias, do atendimento em postos de puericultura e maternidades, além das campanhas nacionais de saúde, a administração pública passou a regular as condutas de cada um destes indivíduos.

Transformar o Estado em um dos maiores provedores de benefícios sociais era uma clara tentativa de sobrepor e complementar o conjunto assistencial proposto pela filantropia. Sendo os sistemas de ajuda uma eficiente ferramenta de regulação das condutas, nada mais vantajoso ao Estado do que ser um de seus maiores provedores. Assim, em discurso publicado no Jornal do Brasil de 08 de novembro de 1935, o médico Olinto de Oliveira, chefe da Diretoria de Proteção à Maternidade e à Infância, exemplificava a importância da estatização dos sistemas de assistência social para a maternidade e a infância:

Um equívoco e certamente muito comum, é o que atribui a proteção oficial a infância deveres de simples caridade e beneficência. O Estado deve socorrer a criança pobre, a criança desvalida, o órfão abandonado, eis a opinião geralmente enunciada. É a ampla transferência para o Estado das obrigações da lei moral até então assumidas pelos indivíduos ou por agrupamentos apropriados, quer por virtude de prescrições religiosas quer por simples comiseração e solidariedade humana. [...] Daí essa atenção especial com que governos civilizados competem encarar a criança, fazendo dela objeto de um conjunto de leis, de organizações capazes de promover seu bem estar, preservar-lhe a vida e a saúde, assegurar-lhe o 
desenvolvimento normal e prestar-lhe assistência e proteção (sic). ${ }^{2}$

A preocupação com a criança e a mãe, particularmente com a mortalidade infantil, o menor abandonado, a delinquência, a desnutrição, a mortalidade materna e a gestação saudável, foi o principal tema que pautou o sistema assistencial brasileiro organizado entre os anos de 1930 e 1940. No entanto, foi com a Era Vargas, empenhada em forjar um novo homem nacional, que a tarefa de proteger as mães e as crianças tornou-se realmente uma preocupação estatal articulada desde os níveis federais até os locais.

Salvaguardar a infância, defender seus direitos, significava por consequência resguardar o próprio desenvolvimento da nação, pois a imagem que se divulgava da criança estava intimamente ligada à noção de progresso e de cidadania e por isso, conforme assinala o jurista Alfredo Tranjan, "[...] afirmou a Constituição que a infância [deve] ser objeto de cuidados e garantias especiais por parte do Estado, que tomará todas as medidas necessárias destinadas a assegurar-lhes condições físicas e morais de vida sã [...]". ${ }^{3}$

Ao estabelecer que a criança fosse um indivíduo a ser assistido, amparado e protegido, indiretamente o Estado Varguista elencava a mãe como sua principal guardiã e responsável. Instrumentalizada, a mulher como sujeito autônomo foi quase anulada na Constituição de 1937, pois suas expectativas e anseios particulares foram condicionados à maternidade. A cidadania plena, que abarcava direitos sociais, políticos e econômicos, somente era exercida se as mães estivessem inseridas no contexto familiar estável, sendo tais benefícios ampliados com o nascimento de uma criança no interior de um casamento.

Desta forma, podemos aferir que a condição das mulheres durante a Era Vargas, bem como no período posterior, estava indubitavelmente atrelada a sua condição de boa mãe e esposa,

2 OLIVEIRA, Olinto. A Proteção a infância no Brasil. In: Jornal do Brasil. Rio de Janeiro, 08 de Novembro de 1935. p. 10.

3 TRANJAN, Alfredo. Getúlio Vargas e a família. In: Revista Ciência Política. Fascículo 03, Volume 02. Rio de Janeiro. Outubro de 1941. p. 46. 
criando um determinismo que quase sempre as excluía da esfera pública e do pleno exercício da cidadania.

A preocupação com o bem-estar infantil e as condições de vida das mulheres que educariam e zelariam pela saúde e vida dos futuros brasileiros estendeu-se por todo o país. Ora promovida por iniciativas públicas, ora por instituições privadas, de norte a sul do país, levantaram-se inúmeras bandeiras em favor da maternidade e da infância saudável, pavimentando o caminho para que a vida das mães e das crianças pobres fosse esmiuçada em busca de desvios que contribuíssem para a depauperação da família brasileira.

Dirigidas basicamente por homens, as instituições assistenciais, públicas ou privadas, apesar de suas preocupações maternalistas ancoraram-se sobre os pressupostos do paternalismo, que por sua vez definia a mulher e a criança como indivíduos passíveis de tutela devido a sua suposta fragilidade física e moral. Apesar de criarem políticas que focavam especificamente nas mulheres mães, tais instituições não se preocuparam em ouvir as reais necessidades femininas relativas à gestação e cuidados infantis, impondo de maneira vertical e hierarquicamente calcada em pressupostos tradicionais de gênero um modelo de maternidade que naturalizava a relação mãe e filho e a colocava sobre a tutela do Estado.

Dentre os discursos sobre a maternidade e a infância que dominavam a cena médica brasileira, nenhum teve tanto poder simbólico quanto aqueles relacionados à mortalidade infantil. $\mathrm{O}$ medo de perder as crianças em tão tenra idade autorizou a corporação médica a esmiuçar o cotidiano das populações pobres em busca das causas relacionadas à mortalidade e estabelecer na relação mãe e filhos o principal foco de sua ação. Para esta "nova" medicina, desenvolvida no Brasil na primeira metade do século passado, não importava apenas saber quais doenças levavam a um número maior de óbitos, lesionando a nação.

O que realmente importava era saber que estas pessoas não morreriam mais de doenças que podiam ser prevenidas e curadas através da construção se um saber sobre o homem saudável, do homem não doente, idealizando os indivíduos através de uma espécie modelo. Neste contexto de apreensão do indivíduo pela medicina, a mulher passou por um ininterrupto processo de aculturação sanitária, 
o seu papel deixava de ser apenas o de transmitir bens materiais e fortunas pessoais, sua função a partir desse momento passava a ser essencialmente instrumental, instância primeira e imediata da medicalização das crianças, garantindo o pleno desenvolvimento de sua prole em benefício do Estado.

\section{A Região Carbonífera Catarinense: a mortalidade infantil e os discursos médicos}

Não muito diferente do que ocorria em outras regiões do país, fosse nos paupérrimos grotões do Nordeste ou nas desenvolvidas áreas urbanas do Sudeste, o problema da mortalidade também era um grave problema do Complexo Carbonífero Catarinense, principalmente no período que compreendeu os anos 1940 a 1960, quando a região chegou ao seu ápice exploratório. Os discursos sobre a situação da infância na região eram diversificados e abarcavam inúmeros aspectos da vida pueril, no entanto, devido a seu forte impacto sobre o sistema econômico, nenhum chamou tanto atenção dos médicos e das autoridades públicas como os elevados índices de mortalidade infantil existentes na cidade e seu entorno.

Em 1944, ao chegar ao complexo carbonífero e se instalar na cidade de Criciúma como funcionário do Departamento Nacional de Produção Mineral, o médico sanitarista Francisco de Paula Boa Nova Junior afirmava que a "[...] mortalidade infantil foi um grave problema que despertou nossa atenção em 1944, [...] pelo elevado número de enterros de crianças que eram vistos diariamente pelas ruas da cidade ( 8 a 10, em média)". ${ }^{4}$

Este discurso alarmista, que denunciava o número excessivo de mortes entre a população infantil local, alastrou-se por outros estratos da sociedade envolvendo autoridades políticas, médicos e

4 BOA NOVA JUNIOR, Francisco de Paula. Problemas médico-sanitários da indústria carvoeira. Ministério da Agricultura: DNPM, 1953. p. 22. 
filantropos, que numa espécie de cruzada pela salvação infantil buscavam alertar os governantes para tão degradante situação que envergonhava a Região Carbonífera Catarinense e especialmente a cidade de Criciúma. Alinhado ao tom denunciante que Boa Nova Junior utilizava em seu relatório, o deputado Jorge Lacerda também explorava tais cifras como uma forma de convencer o Governo Federal e seus pares sobre a importância de promover medidas salutares que protegessem a maternidade e consecutivamente a população infantil.

É com profunda tristeza que trago ao conhecimento da Câmara dos Deputados uma revelação amarga. Em Guatá, grande produtor de carvão, nasceram em 1948, exatamente duzentas crianças. E dessas duzentas crianças, Srs. Deputados, já morreram $170 .^{5}$

Ao apresentar estes dados que foram recolhidos no ano de 1948, quando o deputado Jorge Lacerda esteve na região para investigar a questão social, o Relator da CPI do Carvão tinha a intenção de estabelecer um paralelo entre os investimentos recebidos nas áreas exploratórias e a falta de sensibilidade destas mesmas autoridades públicas e dos mineradores locais em investir na proteção social das famílias operárias, que inevitavelmente refletia-se diretamente sobre a vida das crianças. Mesmo com a existência de uma enraizada retórica que exortava a criação de um aparelho estatal de proteção às crianças e às mães pobres, tais medidas com muita dificuldade se aplicavam nos grandes centros urbanos e nas periferias, e no interior do país, como em Criciúma, esta aplicação era ainda mais precária.

Elemento tão comum à região carbonífera, a mortalidade infantil demonstrava sua pior face na cidade de Criciúma. Concentrando a maioria das minas de carvão, bem como a maior

p. 946. 
parte das famílias operárias, o médico Manif Zacharias ${ }^{6}$ afirmava que a cidade era sempre lembrada em diversas partes do país pela existência de dois elementos comuns: "a terra, por suas particularidades: uma, o carvão, expressão de sua riqueza no sub-solo; outra a elevada mortalidade infantil, traduzindo a miséria de seu povo".

Impulsionados pela ideia de modernização e progresso, que por sua vez acreditavam serem incompatíveis com a miséria e o descaso com a infância, os médicos da cidade como Manif Zacharias e Francisco de Paula Boa Nova Junior realizaram uma série de estudos empíricos para identificar a origem dos problemas que afetavam as crianças contribuindo para a sua expressiva mortalidade.

Formados em grandes centros urbanos, ambos tinham uma ideia ampla de qual era o papel da medicina no processo civilizador brasileiro, principalmente a função da puericultura, que entre as ciências médicas estava encarregada de moldar a maternidade e talhar a criança em seus mínimos detalhes contribuindo para a "geração dos normais, dos sadios e dos fortes [empenhando-se] a fundo para corrigir as múltiplas causas e fatores que concorrem para a decadência da raça $[\ldots]]^{\prime \prime}$. (sic). ${ }^{7}$

$\mathrm{Ou}$ seja, semente das populações futuras, a criança e sua infância passaram a ser os principais alvos de uma intensa campanha médico-sanitária que visava prolongar essa etapa da vida. Para alcançar tal objetivo, as sociedades modernas criaram regras que se impunham tanto para os pais quanto para os filhos, referentes a cuidados com higiene, limpeza, alimentação e amamentação, ou seja, uma série de investimentos necessários ao bom desenvolvimento físico desses pequenos indivíduos até a fase adulta.

Fosse realizada em grandes centros urbanos ou em cidades pequenas do interior como Criciúma, a puericultura brasileira estava intimamente atrelada às escolas carioca e baiana de pediatria, que eram responsáveis por formar um grande número de profissionais desta área. Para o destacado pediatra baiano Martagão Gesteira, a

7 BOA NOVA JUNIOR, Francisco de Paula. Op. Cit. p. 24. 
puericultura era uma arte médica de máxima relevância para o aperfeiçoamento da população e concorria lado a lado com a eugenia na construção de uma raça aperfeiçoada.

De acordo com este autor, em seu tratado de puericultura amplamente difundido entre os pediatras nacionais, esta ciência médica possuía o objetivo de "proteger a criatura humana contra os múltiplos perigos que a ameaçam, desde os primórdios de sua formação e desenvolvimento, até o término da infância", zelando por seu desenvolvimento morfológico e principalmente psíquico. ${ }^{8}$

Imbuídos do sentimento de responsabilidade sobre as populações pobres, principalmente sobre o bem-estar das mães e das crianças, os sanitaristas e puericultores de Criciúma desempenharam um importante papel no estudo e no atendimento à infância exposta aos impactos negativos do processo exploratório do carvão. Autorizados pelo Estado, estes profissionais da saúde passaram a fazer parte do espaço social em que circulavam os pobres urbanos. Ocupando postos de destaque na administração das cidades industrializadas, os médicos analisaram meticulosamente o cotidiano das populações operárias, em especial o estado de saúde das crianças, suas condições de vida e habitação, seus hábitos e costumes, com a finalidade de propor normativas que revertessem os efeitos negativos das doenças sobre a vida infantil. ${ }^{9}$

Seguindo esta lógica, Francisco de Paula Boa Nova Junior foi o primeiro médico na cidade de Criciúma a tentar elaborar um panorama geral das principais moléstias que acometiam a população infantil local, com a finalidade de informar as autoridades sobre a gravidade do problema e apontar para as medidas que poderiam contribuir para a reversão de tal quadro. Em seu relatório o sanitarista descrevia quais eram os fatores que desencadearam as inúmeras mortes relatadas por ele em 1944:

8 GESTEIRA, Martagão. Puericultura: higiene física e social da criança. $3^{\text {a }}$ edição. Rio de Janeiro: Livraria Atheneu, 1957.

9 ALVES, Ismael Gonçalves. Da soberania às biopolíticas: a medicina como instrumento de governo e a inserção da vida biológica na contemporaneidade. In: Revista Contemporâneos: Revista de Artes e Humanidades. v. 09. Santo André: UFABC, 2011. 
Buscamos inicialmente as principais causas dêste elevado índice de mortalidade infantil e encontrâ-mo-las, vitimando na maior parte as crianças de 0 a 1 ano de idade, nas doenças gastro-intestinais (salmonelose e disenterias amebiana e bacilar, entre as mais freqüentes), doenças do aparelho respiratório (pneumonia e broncopneumonia, bronquite capilar, crupe, coqueluche e gripe), doenças infecto-contagiosas em geral, e, principalmente, sub-nutrição. (sic). ${ }^{10}$

Ora relacionada à degradação do ambiente, ora apontada como resultante da falta de preparo das mães em zelar pelo bem-estar dos pequenos, a mortalidade infantil local foi também vinculada à pré-existência de uma série de fatores que unidos criavam a atmosfera perfeita para seu recrudescimento. As doenças gastrointestinais destacadas por Boa Nova Junior estavam atreladas à inexistência de água encanada ou de boa qualidade que pudesse ser oferecida às populações periféricas.

Afetando principalmente o núcleo operário, esta falta de um sistema básico de saneamento e distribuição de água potável era apontada como um dos principais vetores para a disseminação de doenças infectocontagiosas entre a população pueril. De extrema preocupação para médicos e puericultores, a conservação e potabilidade das águas de uso doméstico, principalmente aquelas destinadas para alimentação e asseio infantil, sempre figuraram nos manuais de economia doméstica, higiene e puericultura como um elemento de especial atenção, devido à facilidade com que certas doenças eram propagadas por este meio.

No manual elaborado pelos médicos Henrique Grenchi e Helena Rossi Penna, as mães são alertadas sobre a importância de zelar pela pureza das águas em locais não servidos por uma rede regular de abastecimento conseguindo-as "por meio de poços, que 
devem ser perfurados em lugares limpos, longe de habitações, sem perigo de contaminação por água usada ou por fossas". ${ }^{11}$

No entanto, conseguir água potável nas vilas operárias de Criciúma não era uma tarefa fácil. Rodeadas de rejeito de carvão por todos os lados e servidas por pequenos lagos e açudes que estavam contaminados por enxofre, a única alternativa encontrada pelos moradores dos bairros operários era perfurar poços artesianos e construir pequenas cisternas neste ambiente degradado.

Utilizadas por todos os moradores da casa e consequentemente pelas próprias crianças, a água disponível por este meio de captação, em sua grande maioria, estava contaminada e contribuía para a propagação de doenças. De acordo com Boa Nova Junior, a água destinada à população infantil, fosse ela utilizada no preparo de alimentos ou servida in natura, era de péssima qualidade e só contribuía para o acirramento dos casos de morte e infecções:

[...] esta água empregada na alimentação das criancinhas [...] provinha, quase sempre, de poços e cisternas enlameadas, cheios de sapos, a maioria deles situada nas vizinhanças de tôscas "patentes" de madeira, com fossas rudimentaríssimas, poluídos, portanto por uma abundante flora microbiana, altamente nociva ao delicado organismo das criancinhas sub-nutridas. (sic). ${ }^{12}$

Além da água de péssima qualidade, outro fator que também chamava a atenção dos médicos sobre o cotidiano infantil nas vilas operárias da cidade era o convívio rotineiro entre crianças e animais domésticos de pequeno porte, que também serviam como vetores para doenças gastrointestinais. Porcos, cabras, galinhas e até mesmo gado leiteiro eram comumente criados entre as famílias operárias como uma alternativa de prover sua subsistência devido aos baixos salários e os elevados preços dos alimentos praticados na região.

11 GRECHI, Henrique; PENNA, Helena B. Rossi. Economia doméstica e puericultura. São Paulo: Edições Melhoramentos, 1954. p. 35.

12 BOA NOVA JUNIOR, Francisco de Paula. Op. Cit. p. 22. 
De acordo com Martine Segalen, a prática de criar animais de pequeno porte para o consumo doméstico foi muito comum entre os grupos familiares que se deslocavam do campo e se instalavam em aglomerados urbanos em busca de emprego. Sem familiaridade com as regras do mundo urbano-industrial, estes novos operários levaram consigo fragmentos de seu modo de vida anterior, criando em seu novo local de habitação um ambiente híbrido entre o urbano e o rural.

No entanto, esta prática tão comum no mundo rural e que faz parte da identidade campesina representava sérios riscos para a saúde coletiva no mundo urbano, pois sem o espaço necessário para o trato dos animais, sem as condições sanitárias requeridas para o descarte dos excrementos e o convívio próximo de seres humanos, transformavam-nos em importantes vetores de doenças com rápidos mecanismos de contaminação.

Assim, ao buscar no contexto das vilas operárias de Criciúma outros fatores que contribuíam para a mortalidade das crianças o médico Manif Zacharias chamou atenção para o convívio "promíscuo" entre crianças e animais domésticos que somados a fatores de ordem ambiental criavam o habitat perfeito para que a morte ceifasse centenas de vidas infantis. Para o médico, "a ignorância e a miséria, de mãos dadas, gerando promiscuidade entre crianças e adultos doentes ou animais, o uso quotidiano de água poluída, e alimentos de baixo valor nutritivo tanto pela qualidade, como pela quantidade" contribuíam para a sustentação de tão desoladora paisagem. ${ }^{13}$

Fomentado em grande parte pelos problemas apontados anteriormente, em 1945 o médico sanitarista Boa Nova Junior afirmava terem morrido na cidade de Criciúma cerca de 200 crianças de até um ano a cada mil nascimentos, o que para uma cidade de pequeno porte era considerado algo assustador e inaceitável. Concordando em inúmeros pontos sobre as causas da mortalidade da cidade e da região carbonífera, Manif Zacharias discordava dos números apresentados por Boa Nova Junior, aventando inclusive a 
possibilidade de tais discursos alarmistas serem fruto de folclore local.

Com a intenção de verificar a veracidade de tais discursos, o médico iniciou um estudo empírico, publicado em um jornal local, para identificar o quanto "de realidade havia na afirmação generalizada de que apresentamos um dos maiores índices de mortalidade infantil de todo o país, é cousa que, nos parece, que ninguém ainda, entre nós, procurou averiguar". ${ }^{14}$

A intenção de realizar tal tarefa era impor a autoridade médica como legitimadora de condutas e fonte de verdades, pois "causos" difundidos por moradores e lembranças de tempos passados não serviam de base empírica para a ação médica, que dependia da racionalidade científica para construir seu espaço de atuação. Dessa forma, a racionalidade médica aceitava apenas como evidências dados científicos relacionados ao estudo de estatísticas, de crescimento vegetativo (nascimentos e mortes), epidemias, estudos demográficos e a reorganização do espaço urbano, que por sua vez seriam capazes de apresentar diagnósticos precisos sobre determinado assunto.

Baseado nesta premissa, o médico Manif Zacharias, que exerceu a medicina em Criciúma entre os anos de 1944 e 1966, decidiu verificar se os discursos que afirmavam que a cidade seria a capital brasileira da mortalidade infantil eram realmente verídicos. Percorrendo os três cartórios distritais existentes, Manif Zacharias analisou os registros de nascimentos e óbitos comunicados entre os anos de 1946-1956, e para sua surpresa os discursos sobre os elevados índices de mortalidade entre a população pueril não se confirmaram, assim como

[...] a referência 10 a 12 enterros de crianças por dia não passava de exagero (e dos bem exagerados) provindo de 
generalizações de ocorrências acidentais e esporádicas, verificada, quiçá, por ocasião" de surtos epidêmicos. ${ }^{15}$

Das 4.264 mortes contabilizadas no período estudado, referentes à cidade de Criciúma e os distritos de Nova Veneza e Içara, foram atribuídos 1.992 às crianças de até um ano de idade. Para entender melhor os índices de mortalidade ${ }^{16}$ locais, Manif Zacharias apresentou dois conjuntos de dados distintos, o primeiro abrangendo a cidade de Criciúma e seus respectivos distritos, enquanto o segundo contemplava apenas Criciúma e seus arredores:

Tabela 1 - Mortalidade Infantil em Criciúma e Região (1946 - 1956)

\begin{tabular}{|c|c|c|}
\hline Ano & Mortalidade Infantil & Mortalidade Infantil \\
\hline & Criciúma/Distritos & Criciúma \\
\hline $\mathbf{1 9 4 6}$ & 106,7 & 133,0 \\
\hline $\mathbf{1 9 4 7}$ & 101,2 & 131,6 \\
\hline $\mathbf{1 9 4 8}$ & 101,8 & 124,7 \\
\hline $\mathbf{1 9 4 9}$ & 88,5 & 108,0 \\
\hline $\mathbf{1 9 5 0}$ & 65,7 & 80,3 \\
\hline $\mathbf{1 9 5 1}$ & 82,7 & 98,0 \\
\hline $\mathbf{1 9 5 2}$ & 77,7 & 94,3 \\
\hline $\mathbf{1 9 5 3}$ & 89,9 & 101,7 \\
\hline $\mathbf{1 9 5 4}$ & 80,9 & 97,0 \\
\hline $\mathbf{1 9 5 5}$ & 81,7 & 92,8 \\
\hline $\mathbf{1 9 5 6}$ & 88,8 & 97,9 \\
\hline
\end{tabular}

Fonte: ZACHARIAS, Manif. Mortalidade infantil em Criciúma. Tribuna Criciumense. Criciúma, 27 de maio/03 de Abril de 1957.

Apesar de não contemplar temporalmente o período que Boa Nova Junior relatou os inúmeros enterros de crianças diários, os números apresentados por Manif Zacharias revelaram uma paisagem

15 Idem.

16 A mortalidade infantil avalia-se pelo chamado coeficiente, isto é, pela relação do número de nascimentos vivos e óbitos de crianças entre 0 e 1 ano de idade, durante o período de um ano civil, calculando-se o número de óbitos a cada 1000 nascimentos. A mortalidade infantil é considerada baixa ou fraca quando o coeficiente é inferior a 40; média ou moderada quando entre 40 e 70; alta ou forte entre 70 e 100, muito elevada ou muito forte acima de 100. 
divergente. ${ }^{17}$ De acordo com o autor, os índices de Criciúma não estavam muito acima da média nacional, apesar de considerada alta na maioria dos anos pesquisados, os números identificados alinhavam-se a outros índices nacionais e até mesmo estaduais.

Ao fazer um comparativo da mortalidade infantil com outras regiões do Brasil como, por exemplo, Florianópolis, o médico advertia que entre os anos 1945 e 1954 os valores variavam entre 211,6 e 99,9 sendo o coeficiente muito elevado em 09 anos e elevado em 01. Neste mesmo período, de acordo com os dados do Instituto Brasileiro de Geografia e Estatística (IBGE), o coeficiente de mortalidade no Distrito Federal era de 106; em Porto Alegre 107; em Belém 110 e em Salvador $162 .^{18}$

Ao apresentarem gráficos sobre a mortalidade e estabelecerem comparações entre diferentes cidades e até mesmo países, os médicos buscavam sensibilizar as autoridades públicas e a sociedade local sobre o descaso e a letargia com que a infância e consequentemente a maternidade eram tratadas. Dessa forma, a constatação de tão elevados índices envolvendo a população infantil respaldava o discurso médico-sanitário a adentrar nos mais recônditos espaços da vida cotidiana das famílias pobres em busca das causas e possíveis motivos para que criaturas em tão tenra idade fossem ceifadas pela morte. ${ }^{19}$

Apesar de ambos os médicos discordarem com relação aos números da mortalidade infantil na cidade, tanto um como outro compartilhavam da mesma opinião no que se referia ao papel das mães e da família sobre a vida infantil. Segundo Manif, além das causas já apresentadas anteriormente os óbitos entre as crianças das famílias mineiras de Criciúma também estavam relacionados aos fatores de classe, "ignorância e miséria, eis a resposta formal,

17 Cabe ressaltar que os números encontrados por Manif Zacharias são referentes apenas aos nascimentos e óbitos legalmente registrados em cartórios oficiais. No entanto, uma característica comum no período e que ainda hoje persiste entre muitas famílias pobres urbanas e rurais é a falta do costume de impetrar junto às autoridades competentes o registro nascimento e óbitos, o que distancia muitas estatísticas elaboradas no século passado da realidade local.

18 ZACHARIAS, Manif. Op. Cit. p. 07. [b]

19 LIS, Irene Palacio. Mujeres ignorantes: madres culpables, adoctrinamiento y divulgación materno-infantil en la primera mitad del siglo XX. Valencia: Univerdidad de Valencia, 2003. 
categórica e imperativa e que deve ser dada corajosamente", pois a mortalidade infantil é "fortemente influenciada pelas questões higiênicas de habitação e alimentação, e pelos fatores econômicos e sociais, que quando desfavoráveis carreiam pobreza e atraso cultural". 20

Corroborando com estas mesmas ideias, Boa Nova Junior, apoiado no discurso classista de demonização das camadas populares urbanas, também afirmava: "É sumamente desagradável e doloroso relatarmos aqui que muitas criancinhas, em Criciúma, pereciam em grande número [...] em virtude do descaso de seus próprios pais, da ignorância de suas mães". ${ }^{21}$

Discurso muito comum entre os profissionais da medicina no século passado a suposta ignorância das mães, aliada à falta de assistência pública, criava o ambiente propício para que a morte fosse uma presença constante entre as crianças das famílias pobres urbanas. Assim como ocorria nos grandes centros urbanos do país, em Criciúma as mulheres também foram alvo de um discurso pediátrico que as apontavam como incultas e preguiçosas, reafirmando a necessidade de educá-las e controlá-las através de normas higiênicas.

Frente a impossibilidade de acabar em um curto espaço de tempo com a mortalidade entre as crianças da cidade, a prioridade dos médicos era diminuir dramaticamente os números de mortes por meio de um intenso processo de reeducação das mulheres. Mesmo a maternidade sendo considerada pela medicina como algo natural e intrínseco a todas as mulheres, a educação sanitária e a puericultura se apresentavam como complemento racionalizado a esta suposta natureza feminina. Segundo estas premissas, por meio da correta educação médica oferecida às mães e às famílias os serviços estatais seriam complementados por uma perfeita simbiose entre os profissionais da medicina, as mães e os serviços estatais de assistência, conforme expõe o Credo da Criança, elaborado pelo DNCr e publicado pela Tribuna Criciumense de 09 de maio de 1955: 
Cremos no futuro do Brasil, pela proteção integral a criança. [...] Cremos que a base do bem estar e do futuro da criança no lar e na família bem organizados. [...] Cremos que na proteção à infância é muito mais importante a influência de pessoal habilitado, experiente e dedicado, que a das condições materiais. [...] Cremos que, para o bem futuro da humanidade, como para o do Estado, da família e do indivíduo, a proteção bem entendida à criança é mais importante e essencial que qualquer outra das atividades dos governos. ${ }^{22}$

Intimamente ligada ao discurso de salvaguarda das crianças, a tutela e culpabilização das mães foi fruto de uma concepção paternalista, patriarcal e conservadora elaborada pela classe médica com a finalidade de atribuir uma causa para a mortalidade na infância. Apesar de dirigirem suas críticas às autoridades políticas e aos sistemas de proteção social, ineficazes e pouco abrangentes, foi sobre as mulheres que recaiu boa parte das premissas tutelares que passaram a demonizar as tradicionais formas de cuidado com as crianças. Sem enfatizar com maior clareza o impacto das péssimas condições de vida sobre os infantes, os médicos e os puericultores voltaram sua atenção às mães, que por instinto e natureza deveriam sobrepor todos os obstáculos da pobreza e da miséria cotidiana em favor de seus filhos.

Partindo das classes dominantes, o discurso médico condenava autoritariamente as tradicionais práticas de cuidados com a infância, transmitidas oralmente de geração para geração e que expressavam o saber autônomo das mulheres, como por exemplo o uso de farinhas alimentícias em substituição ao leite materno, de xaropadas para a cura de moléstias, utilização de chupeta, entre outros. Percebidas como ignorantes, as mães deveriam ser tuteladas pelos preceitos regeneradores da ciência, que forneceriam novos modelos para antigas práticas consideradas anti-higiênicas, baseadas em superstições e crendices. Por serem consideradas as responsáveis 
diretas pelo bem-estar e/ou pelo mal-estar das crianças, as mães eram sempre culpadas pelas doenças e morte que atingiam seus filhos.

Em Criciúma, este discurso de culpabilização das mães e a intromissão no mundo dos tradicionais cuidados infantis estavam, principalmente, atrelados à alimentação e dietética das crianças. Para os médicos Boa Nova Junior e Manif Zacharias, o primeiro problema a resolver no âmbito familiar era modificar costumes maternos relativos à alimentação na primeira infância. Para ambos, imersas no mundo da ignorância, as mães das camadas populares eram pouco atentas às questões básicas de higiene no preparo dos alimentos e transformavam o tão precioso leite materno em alimento secundário na vida do infante. Em seu relatório, Boa Nova Junior chamava a atenção para um dos motivos alegados pelas mulheres para substituir o leite materno por uma alimentação considerada artificial e deficitária em nutrientes:

[...] sob a infundada alegação de que seu leite era fraco, desmamavam-nas [as crianças] logo às primeiras semanas de vida, substituindo o preciosíssimo leite materno por pirão de farinha de mandioca, feito simplesmente com água. ${ }^{23}$

Nos anos de 1950 já estava estabelecido um sólido discurso sobre as benesses oriundas da amamentação materna nos primeiros meses de vida da criança, sustentado pelos discursos da nutrição infantil que solidificava-se como um campo específico da puericultura. As justificativas em defesa do aleitamento materno evocavam de maneira geral seu caráter natural e nutritivo; uma composição quase mística que criava um elo indissolúvel entre a mãe e a criança.

Além das propriedades nutritivas amplamente apregoadas, havia um forte discurso de gênero que considerava uma mãe completa somente aquelas que nutriam seus filhos com o alimento 
disponibilizado pelo seu próprio corpo. ${ }^{24}$ Conforme afirma o pediatra Martagão Gesteira, esta é a "obrigação que tem tôda mãe, digna dêsse nome, tôda mãe que queira ser, no conceito de Marco Aurélio, "mãe inteira", de continuar a assegurar por algum tempo, com o leite que lhe flue dos seios [...]". (sic). ${ }^{25}$

Apesar de no pensamento maternalista a amamentação figurar como um ato que cria elos naturais entre mãe e filho, símbolo da verdadeira feminilidade (Weiner, 1994), para os médicos o aleitamento não poderia continuar no mundo da natureza, como algo instintivo, pois dessa maneira ele em nada contribuiria para o desenvolvimento da criança. Uma vez mais, se apropriando de uma prática ensinada pela oralidade entre as mulheres, a medicina em nome do bem-estar das crianças submeteu a amamentação ao mundo das ciências e a racionalizou de acordo com uma metodologia. Dessa forma, o aleitamento passou a ser regrado de acordo com normas higiênicas, explicado segundo os cânones da puericultura e transformado em um processo pedagógico, com uma infinidade de regras e normas que deveriam ser observadas à risca.

Um exemplo disso foi a divulgação do Livro das Mães, publicado pelo Departamento Nacional da Criança (DNCr) em 1955 que fazia uma ávida defesa do aleitamento materno salientando as propriedades específicas existentes no leite humano, de fácil ingestão "pois coagula no estômago em grumos muito pequenos e porque possui fermentos digestivos que auxiliam na digestão". ${ }^{26}$

Este livro estava dedicado às diversas etapas da vida da criança, no entanto trazia um capítulo específico sobre a amamentação com regras, horários, posições, higiene dos seios, regulação da vida alimentícia da nutriz, que transformavam o ato de amamentar em algo quase científico e difícil de ser cumprido em todos os seus ditames. Além disso, o livro afirmava categoricamente a inexistência de "leite fraco", suspeita que "costuma-se instalar na mente das nutrizes estimuladas pelas vizinhas e amigas 'entendidas'

24 GARRIGÓS, Lucía Provencio. La trampa discursiva del elogio a la maternidad cubana del siglo XIX. In: Americania. N 1. Sevilla: Universidad Pablo de Olavide, 2011.

25 GESTEIRA, Martagão. Op. Cit. p. 74.

26 DNCr. Livro das mães. $3^{\mathrm{a}}$ edição. N. 143. Rio de Janeiro: Departamento Nacional da Criança, 1955. p. 116. 
em crianças" ${ }^{27}$, reforçando a ideia de que a amamentação só poderia ser abandonada com a expressa autorização médica depois de exames detalhados na criança, e só após este procedimento o puericultor indicaria então um substituto para o leite da mãe.

No caso de Criciúma a reclamação médica sobre a substituição autorizada do leite materno estava relacionada à dificuldade das mães pobres em adquirir o leite de origem bovina ou caprina. Nas palavras de Manif Zacharias esta situação de miséria "priva a criança pobre, o lactente (a expressão significa - que ainda mama) de seu alimento essencial, o leite, substituído em inúmeros casos constatados na clínica diária, pelo pirão ou pelo mingau de farinha e água". ${ }^{28}$ Da mesma forma relatava Boa Nova Junior:

Indagamos de muitas mães porque, então, ao suprirem o aleitamento materno não ministravam o leite de vaca, de mistura com água, ou o leite de cabra ou o leite em pó. Porque, - nos respondiam (e nisto lhes dávamos razão), o leite de vaca dificilmente se obtém em Criciúma e, nas épocas que existe, o seu preço é inacessível para a bolsa do operário (3,80 o litro); o leite de cabra também é caro e alguns poucos mineiros, que as criam em suas próprias residências, têm-nas para obtenção de leite para seu próprio consumo $[\ldots]{ }^{29}$

No entanto, mesmo com a precariedade do modo de vida operário e os diversos fatores de ordem econômica e social que contribuíam para a mortalidade das crianças, os médicos da cidade continuavam centrando sua atenção sobre as mães. De acordo com os preceitos da puericultura difundidos por Martagão Gesteira, ${ }^{30}$ em nada adiantava os governos estabelecerem grandes redes assistenciais se as mulheres mães não estivessem convencidas de seu papel como

27 Idem, p. 125-126.

28 ZACHARIAS, Manif. Mortalidade infantil em Criciúma. In: Tribuna Criciumense. Criciúma, 03 de abril de 1957. p. 07. [c]

29 BOA NOVA JUNIOR. Francisco de Paula. Op. Cit. p. 23.

30 GESTEIRA, Martagão. Op. Cit. 
protetoras da infância e não fossem educadas de acordo com os preceitos da medicina, pois boa parte do desenvolvimento infantil se dava em casa sob a supervisão da família. Orientar, aconselhar e formar as mães de acordo com os princípios da puericultura era a maneira mais eficaz de combater a mortalidade na ausência de um Estado protetor.

Assim, a autoridade médica, patriarcal e conservadora apresentava-se como a única capaz de guiar e educar as mães pobres, que devido a sua origem social e a suposta falta de uma cultura letrada denotava a necessidade de ação tutelar que as afastaria da ignorância. Para Francisco de Paula Boa Nova Junior, fazia-se necessário criar entre as mulheres das camadas populares urbanas de Criciúma uma cultura da boa maternidade, na qual as mães por meio de aconselhamentos e imposições médicas se adaptariam às necessidades dos novos tempos e abandonariam as formas tradicionais de cuidados infantis:

Por estas razões, empreendemos uma árdua tarefa de educar as mães, de orientá-las, de aconselhá-las no sentido de mostrar o caminho certo que deveriam seguir para bem alimentar seus filhinhos, para bem criá-los e para preservar-lhes a saúde, e portanto a vida [...]. ${ }^{31}$

Apresentando-se como o guia capaz de indicar o bom caminho, o médico sanitarista alocava as mulheres em um papel secundário, imputando-lhes a responsabilidade de cuidar seus filhos por meio dos métodos tradicionais passados de mãe para filhas. Sob a alegação de salvaguardar a infância, a corporação médica adentrou na vida das mulheres pobres com a intenção de mudar antigos hábitos e valores, considerados rudes e infundados, por novos, mais higiênicos, modernos e amparados pelos preceitos da medicina.

Baseado nesta premissa, assim afirmava o médico Martagão Gesteira em seu livro de puericultura: "A luta contra a miséria, o 
amparo econômico, a assistência a maternidade, moral e sanitária" que as medidas legislativas e outras obras assistenciais procuram assegurar "à infância e à maternidade não bastam [...] se não se atende outro grande fator responsável por todos esses males [...]: a ignorância. ${ }^{32}$

Recorrendo à autoridade de Martagão Gesteira, o médico Manif Zacharias ${ }^{33}$ escrevia em seu artigo que o referido autor estava correto em afirmar que quanto maior a ignorância "e mais baixas as condições de uma coletividade, maior é a incidência de mortalidade infantil", daí a necessidade de amparar moral, econômica e socialmente as mães de Criciúma e seus arredores. Tanto para Boa Nova Junior quanto para Manif Zacharias, entre outros, a Região Carbonífera estava completamente despreparada para enfrentar os problemas da maternidade e a infância, recebendo apenas medidas sanitário-sociais paliativas e esporádicas que,

[...] vez por outra obedecendo a determinação de Departamentos e Secretarias, em comemorações festivas da Semana da Criança, ou do Dia da Raça, em que, na série interminável de discursos e palestras são exaltados os pequenos entes, radiosa esperança da Pátria estremecida. Pobre Pátria, em que os monumentos aos maiores feitos de seus filhos se originem nos cemitérios. $^{34}$

Sendo o grande problema da Região Carbonífera Catarinense, a mortalidade infantil foi por anos alvo de um enérgico discurso moral que responsabilizava as famílias e principalmente as mulheres pobres pelo elevado número de mortes entre a população infantil. Colocando a assistência que deveria ser prestada pelo Estado em um plano secundário, a pobreza e a ignorância foram elencadas como fatores preponderantes para tão elevados índices. 
Em nome da nacionalidade e da construção de um país de homens hígidos, as mulheres mães tiveram suas vidas esmiuçadas pelo poder médico que transformou toda e qualquer prática de cuidados não avalizadas pela medicina em um ato de transgressão e descaso com o futuro do país. Inseridas em um contexto de miséria, as mulheres das vilas operárias foram alvo de um forte discurso moral e de gênero que lhes impunha um modelo normativo de maternidade que quando não observado e praticado em seus mínimos detalhes justificava a ação impositiva da corporação médica sobre as tradicionais formas de vida, transformando-as em únicas culpadas do atraso pela depauperação física e moral do país.

RECEBIDO EM: 01/03/2017 APROVADO EM: 01/06/2017 